\title{
Antibacterial properties of Tualang, Acacia and Yemeni Sumur honey against selected food spoilage bacteria and foodborne pathogens
}

\author{
${ }^{1}$ Yousof, K., ${ }^{1, *}$ Nor-Khaizura, M.A.R., ${ }^{2}$ Nur Hanani, Z.A. and ${ }^{2}$ Ismail-Fitry, M.R. \\ ${ }^{1}$ Department of Food Science, Faculty of Food Science and Technology, Universiti Putra Malaysia, 43400 \\ Serdang Selangor, Malaysia \\ ${ }^{2}$ Department of Food Technology, Faculty of Food Science and Technology, Universiti Putra Malaysia, \\ 43400 Serdang Selangor, Malaysia
}

\begin{abstract}
Article history:
Received: 5 August 2019

Received in revised form: 5

October 2020

Accepted: 28 January 2021

Available Online: 13

February 2021

Keywords:

Honey,

Minimum Inhibitory

Concentration,

Minimum Bactericidal

Concentration,

$\mathrm{pH}$,

water activity
\end{abstract}

DOI:

https://doi.org/10.26656/fr.2017.5(1).270

\begin{abstract}
The antibacterial activity of honey is mainly credited to its acidity, osmolarity and enzymatic generation of hydrogen peroxide via glucose oxidase. Additional honey components, such as aromatic acids or phenolic compounds, also contribute to the overall antibacterial activity. The level of antibacterial activities found in honey varies with different types of honey, due to mainly the composition, percentage as well as the nature of the sugars present in the honey. This study aimed to evaluate the antibacterial activity of four types of honey, namely Tualang honey $\left(\mathrm{TH}_{1}\right)$, Tualang honey $\left(\mathrm{TH}_{2}\right)$, Acacia honey (AH) and Yemeni Sumur honey (YSH). Nine bacterial strains were used. Disc diffusion, well diffusion, minimum inhibitory concentration (MIC), Minimum bactericidal concentration (MBC), and time-kill methods were performed to reveal the antibacterial potential of the selected honey. The MIC values ranged between 12.5 to $50 \%$ for both $\mathrm{TH}_{1}$ and $\mathrm{YSH}$ while for $\mathrm{TH}_{2}$, and $\mathrm{AH}$ it ranged between 25 to $50 \%$. For $\mathrm{MBC}$, it ranged from 25 to $50 \%$. The time-kill in $\mathrm{TH}_{1}$ Staphylococcus aureus (food isolate) showed total inhibition at $6 \mathrm{hrs}$ in 2 X MIC, and for Staphylococcus aureus ATCC 29737 was $3.84 \mathrm{log}$ $\mathrm{CFU} / \mathrm{g}$ at the $6 \mathrm{hrs}$. Physicochemical quality of honey resulted as follows: the $\mathrm{pH}$ of the honey samples was acidic in nature ranging between 3.69 to 3.94 , and the $\mathrm{a}_{\mathrm{w}}$ of the honey samples were between 0.53 to 0.69 . For colour analysis, YSH was observed to has the maximum lightness and yellowness, and $\mathrm{TH}_{1}$ has the maximum redness. While, $\mathrm{AH}$ had a minimum lightness, redness, and yellowness.
\end{abstract}

\section{Introduction}

Honey is characterised as a vicious, aromatic and sweet food substance that many people around the world enjoy its consumption. Since ancient times, honey has been used in medical treatment as an antiseptic until the antibiotics were invented. However, the treatment of diseases has become more difficult than ever due to the emergence of antibiotic-resistant bacteria. As a result, humans seek a natural alternative such as honey to treat diseases. Honey contains antibacterial compounds that are effective in killing or inhibiting a broad spectrum of bacteria (Boukraâ, 2013). Various studies have shown that honey is effective against a wide range of microorganisms, including methicillin-resistant Staphylococcus aureus (MRSA) and vancomycinresistant enterococci (VRE).

For all antibiotic classes, including the major last- resort drugs, resistance is increasing worldwide and even more alarming, very few new antibiotics are being developed. The potent activity of honey against antibiotic-resistant bacteria resulted in renewed interest for its application. Several types of honey have been approved for clinical applications. The incomplete knowledge of the antibacterial compounds involved and the variability of antibacterial activity are, however, major obstacles for applicability of honey. Therefore, the objective of this work is to determine the in vitro antibacterial activity of Tualang Honey $1\left(\mathrm{TH}_{1}\right)$, Tualang Honey $2\left(\mathrm{TH}_{2}\right)$, Acacia Honey $(\mathrm{AH})$ and Yemeni Sumur Honey (YSH) against foodborne pathogens and spoilage bacteria. 


\section{Materials and methods}

\subsection{Honey samples}

In this study, four honey samples were used. Tualang Honey $1\left(\mathrm{TH}_{1}\right)$ is from Federal Agricultural Marketing Authority (FAMA), Malaysia. Tualang Honey $2\left(\mathrm{TH}_{2}\right)$ is from MAM Industries, Malaysia. Acacia Honey (AH) is from Summer Pacific Sdn. Bhd., Malaysia. Yemeni Sumur honey (YSH) is from Rayyan Salsabila Sdn. Bhd., Malaysia. The differences between $\mathrm{TH}_{1}$ and $\mathrm{TH}_{2}$ were, therefore, just their brands.

\subsection{Preparation of honey samples}

Honey solutions were prepared by diluting honey to the required concentrations based on two-fold serial dilutions $(0.195,0.390,0.781,1.56,3.125,6.25,12.5$, 25 , and $50 \% \mathrm{w} / \mathrm{v}$ ) to check for the antibacterial activity of honey (CODEX STAN, 1981). The honey solutions were handled aseptically to avoid cross-contamination. All samples were then incubated for 30 mins at $37^{\circ} \mathrm{C}$ in a shaking water bath that allowed aeration of the solutions. Incubation was carried out in the dark because both hydrogen peroxide and glucose oxidase are light sensitive.

\subsection{Test organisms}

Nine bacterial strains were assayed; four were Grampositive Staphylococcus aureus ATCC 29737, Bacillus cereus (food isolate), Staphylococcus aureus (food isolate) and Listeria monocytogenes ATCC 19112, and five Gram-negative Escherichia coli (food isolate), Campylobacter jejuni ATCC 29428, Pseudomonas aeruginosa ATCC 27853, Escherichia coli ATCC 10536 and Salmonella enterica ser. Typhimurium ATCC 13311. Stock cultures of the ATCC were obtained from Thermo Fisher Scientific (US) while the remaining microorganisms were obtained from the culture collection of the Laboratory of Food Microbiology, Faculty of Food Science and Technology, University of Putra (UPM), Malaysia.

\subsection{Preparation of test organisms}

Stock cultures of the bacterial pathogens were subcultured in Nutrient agar (Oxoid, UK) at $37^{\circ} \mathrm{C}$ for 24 hrs. Colonies of fresh cultures of the different microorganisms from overnight growth were picked with a sterile inoculating loop and suspended in 3 to $4 \mathrm{~mL}$ of Nutrient broth (Oxoid, UK) in sterile test tubes and incubated for 2 to $3 \mathrm{hrs}$ at $37^{\circ} \mathrm{C}$. This was diluted with sterile distilled water to standardise the inoculum density used in this study.

\subsection{Antibacterial activity of honey}

\subsubsection{Disc diffusion assay}

Disc diffusion assay was performed to demonstrate the sensitivity of microorganisms to the honey samples with a slight modification in which an overnight bacterial culture was suspended into $5 \mathrm{~mL}$ of $0.1 \%$ normal saline and adjusted with $0.5 \mathrm{Mc}$ Farland standards (Reller et al., 2009). A $50 \mu \mathrm{L}$ of the bacterial suspension was spread well using sterile swabs on Mueller Hinton agar (Oxoid, UK). Sterile paper discs (Whatman AA discs, $6 \mathrm{~mm}$ in diameter) were used to impregnate nine different dilutions of each of the honey samples as follows $(0.195$, $0.390,0.781,1.56,3.125,6.25,12.5,25$, and $50 \% \mathrm{w} / \mathrm{v})$. Twenty microliters of each dilution of honey were soaked into the paper discs and allowed to dry at room temperature and placed aseptically on the surface of inoculated agar using sterile forceps and finally incubated for 16 to $24 \mathrm{hrs}$ at $37^{\circ} \mathrm{C}$. The assessment of antibacterial activity was based on the measurement of the diameter of the inhibition zone appearing around the disc. The sterile blank disc was used as a negative control. As a positive control, ciprofloxacin and gentamicin (Oxoid, UK) were used for Gram-negative bacteria, and for Gram-positive bacteria, ampicillin and penicillin G (Oxoid, UK) were used (Tumin et al., 2005).

\subsubsection{Well diffusion assay}

The procedure was similar to that of disc diffusion assay. Mueller Hinton plates were inoculated with $50 \mu \mathrm{L}$ of $0.5 \mathrm{Mc}$ Farland standard bacterial suspension. A hole with a diameter of 6 to $8 \mathrm{~mm}$ was punched aseptically with a sterile cork borer or a pipette tip, and 100 to 200 $\mu \mathrm{L}$ of honey of different concentrations $(0.195,0.390$, $0.781,1.56,3.125,6.25,12.5,25$, and $50 \% \mathrm{w} / \mathrm{v}$ ) was introduced into the well. Plates were incubated for 16 to $24 \mathrm{hrs}$ at $37^{\circ} \mathrm{C}$. The assessment of antibacterial activity was based on the measurement of the diameter of the inhibition zone appearing around the hole. Sterile distilled water was used as a negative control. As a positive control, ciprofloxacin and gentamicin (Oxoid, UK) were used for Gram-negative bacteria, and for Gram-positive bacteria, ampicillin and penicillin $G$ (Oxoid, UK) were used (Tumin et al., 2005).

\subsubsection{Minimum Inhibitory Concentration (MIC)}

The MIC of different honey samples was determined using the two-fold dilution method (Balouiri et al., 2016). Honey batches were investigated for their MIC against all the nine bacterial strains. About $1 \mathrm{~mL}$ of honey was transferred into each test tube followed by the addition of $1 \mathrm{~mL}$ of Mueller Hinton (Oxoid, UK) broth that contained standardised inoculum of $0.5 \mathrm{Mc}$ Farland to achieve final dilutions of $0.195,0.390,0.781,1.56$, 
$3.125,6.25,12.5,25$, and $50 \%(\mathrm{v} / \mathrm{v})$. The inoculated tubes were incubated at $37^{\circ} \mathrm{C}$ for $24 \mathrm{hra}$. The highest dilution of the tested honey to inhibit growth (no turbidity in the tube) was considered as the MIC value of the honey against the tested bacterial species.

\subsubsection{Minimum Bactericidal Concentration (MBC)}

MBC test was performed following the MIC test via a streak plate method. Each honey dilution with no bacterial growth (turbidity) from the MIC test was assayed. A loopful of bacterial strain was inoculated into sterile Mueller Hinton plates. The plates were then incubated at $37^{\circ} \mathrm{C}$ for $24 \mathrm{hrs}$. The least concentration that did not show any growth of tested organisms was considered as the $\mathrm{MBC}$ value of the tested honey against the tested bacterial species (Balouiri et al., 2016).

\subsubsection{Time-Kill}

Time-kill assay was performed to determine the time taken for the microorganisms to be killed by the honey, and it was performed following the method of Rukayadi et al. (2010). Mueller Hinton broth was used, and bacterial inoculum was adjusted between 6 to $8 \log \mathrm{CFU} /$ $\mathrm{mL}$. Final concentrations of honey were $0 \mathrm{MIC}, 1 / 2 \times$ MIC, $1 \times$ MIC, and $2 \times$ MIC. Four bijou bottles were added with the right amount of the inoculum and the honey respectively to produce the final concentrations of $0 \mathrm{MIC}, 1 / 2 \times \mathrm{MIC}, 1 \times \mathrm{MIC}$, and $2 \times$ MIC aliquots. These steps were performed for all the strains. The cultures were then incubated at $37^{\circ} \mathrm{C}$ with the agitation of 200 $\mathrm{rpm}$. At predetermined intervals $0,1 / 2,1,2,4$ and $6 \mathrm{hrs}, 1$ $\mathrm{mL}$ aliquots were serially diluted in $1 \%$ phosphatebuffered saline (PBS) and plated onto Mueller Hinton (Oxoid, UK). The plates were incubated at $37^{\circ} \mathrm{C}$ for 24 hrs, and the number of colonies was counted. The assays were carried out in duplicate. The graph of $\log _{10} \mathrm{CFU} /$ $\mathrm{mL}$ was plotted against time.

\subsection{Physicochemical activity of honey}

\subsubsection{Determination of $\mathrm{pH}$}

The $\mathrm{pH}$ values of the honey samples $(10 \%$ aqueous honey solution) were measured at $28 \pm 2^{\circ} \mathrm{C}$ using a digital $\mathrm{pH}$ meter (Mettler Toledo) calibrated at $\mathrm{pH} 4.0,7.0$ and 9.0 using standard buffer solutions (Saxena et al., 2010).

\subsubsection{Determination of water activity}

The water activity of honey solutions was determined at $25 \pm 0.2^{\circ} \mathrm{C}$ using an electronic dew-point water activity meter (Aqualab Series 3 model TE, USA) equipped with a temperature-controlled system which stabilised the temperature during measurement (Chirife et al., 2006).

\subsubsection{Colour analysis}

The honey surface colour was measured using a colourimeter (HunterLab, model D25 L optical sensor, Hunter Associates Reston, VA, USA) calibrated with a white and a black standard plate. Honey solution (10 $\mathrm{g}$ of honey in $75 \mathrm{~mL}$ free $\mathrm{CO}_{2}$ distilled water) was placed into a cylindrical (base diameter $11.3 \mathrm{~cm}$ and height $2 \mathrm{~cm}$ ) optical cell. Reflectance values were obtained using a 45 $\mathrm{mm}$ viewing aperture. The results reported were the mean of five determinations (Shafiee et al., 2014).

\subsection{Statistical analysis}

Experiments were performed in duplicate, and the results were expressed as mean values with standard deviations (SD). The significant differences were obtained by one-way analysis of variance (ANOVA, Tukey's test).

\section{Results and discussion}

\subsection{Disc diffusion assay}

For the Disc Diffusion Assay, only S. aureus showed inhibition with a clear zone in all types of honey. For $\mathrm{TH}_{1}$, the inhibition zone at $25 \%$ was $10.08 \mathrm{~mm}$, and at $50 \%$ the inhibition zone was $15.01 \mathrm{~mm}$. For $\mathrm{TH}_{2}$, the inhibition zone at $25 \%$ was $6.25 \mathrm{~mm}$, and at $50 \%$ it was $12.92 \mathrm{~mm}$. For $\mathrm{AH}$, the inhibition zone at $25 \%$ was 8.82 $\mathrm{mm}$, and at $50 \%$ it was $13.06 \mathrm{~mm}$. For $\mathrm{YSH}$, the inhibition zone at $25 \%$ was $12.49 \mathrm{~mm}$, and at $50 \%$ it was $20.35 \mathrm{~mm}$, as shown in Table 1. The diameter of the inhibition zone of the positive control was between 22.00 - $24.24 \mathrm{~mm}$, which was higher than the $50 \%$ concentration of treatments. The rest of the bacteria did not show any inhibition zone. There was a significant ( $p$ $<0.05)$ difference between the samples.

Table 1. Diameter of inhibition zone (DIZ) of Tualang Honey $\left(\mathrm{TH}_{1}\right)$, Tualang Honey $\left(\mathrm{TH}_{2}\right)$, Acacia Honey $(\mathrm{AH})$ and Yemeni Sumur Honey (YSH) against Staphylococcus aureus using Disc Diffusion Assay

\begin{tabular}{ccccc}
\hline \multirow{2}{*}{ Honey } & \multicolumn{3}{c}{ Concentration (\%) } & \multirow{2}{*}{ Control } \\
\cline { 2 - 4 } & $12.5 \mathrm{~mm}$ & $25 \mathrm{~mm}$ & $50 \mathrm{~mm}$ & \\
\hline $\mathrm{TH}_{1}$ & $6.00 \pm 0.00^{\mathrm{c}}$ & $10.08 \pm 0.20^{\mathrm{b}}$ & $15.01 \pm 0.35^{\mathrm{a}}$ & P 22.40 \\
$\mathrm{TH}_{2}$ & $6.00 \pm 0.00^{\mathrm{c}}$ & $6.25 \pm 1.21^{\mathrm{b}}$ & $12.92 \pm 0.66^{\mathrm{a}}$ & P 23.10 \\
$\mathrm{AH}$ & $6.00 \pm 0.00^{\mathrm{c}}$ & $8.82 \pm 0.54^{\mathrm{b}}$ & $13.06 \pm 0.41^{\mathrm{a}}$ & P 24.24 \\
$\mathrm{YSH}$ & $6.00 \pm 0.00^{\mathrm{c}}$ & $12.49 \pm 0.38^{\mathrm{b}}$ & $20.35 \pm 1.07^{\mathrm{a}}$ & P 22.00 \\
\hline
\end{tabular}

Diameter of inhibition zone in $\mathrm{mm}$ (including disc). Values are expressed as mean \pm standard deviation. Values with different superscript within the row are significantly different $(p<$ $0.05)$.

The use of disc could lead to the exclusion of large molecules which are not properly absorbed by the paper disks and may contribute to inaccurate results as honey is 
a complex solution consisting of different sizes of chemicals and compounds (Zainol et al., 2013). Kolayli et al. (2016) examined the antibacterial activities of chestnut honey using a disc, found that the highest inhibition was achieved against pathogenic bacteria such as $S$. aureus, E. coli, Enterococcus faecalis and Yersinia pseudotuberculosis.

\subsection{Well diffusion assay}

In the preliminary screening, all the honey showed various range diameter of inhibition zone (DIZ) against most of the tested bacteria. More than half of the isolates showed antibacterial activity in a concentration between $12.5,25$ and $50 \%(\mathrm{w} / \mathrm{v})$. The inhibitory activity was significantly $(p<0.05)$ affected by the type of bacteria used as well as the honey samples. $\mathrm{TH}_{1}$ and $\mathrm{YSH}$ had the highest DIZ. For $\mathrm{TH}_{1}$, as shown in Table 2, the range was between $15.82 \mathrm{~mm}$ and $31.9 \mathrm{~mm}$, lowest DIZ was seen on $S$. aureus, which was $15.82 \mathrm{~mm}$ at $25 \%$. At 12.5 and $25 \%$, both $E$. and $S$. enterica ser. Typhimurium ATCC 13311 almost showed the same DIZ, which was 18.13 $\mathrm{mm}$ and $18.37 \mathrm{~mm}$, respectively. The DIZ was seen on $S$. enterica ser. Typhimurium ATCC 13311 at 50\%, which was $31.95 \mathrm{~mm}$. S. aureus ATCC 2973, E. coli, and $C$. jejuni ATCC 29428 were almost in the same range 25.88, 25.23 and $25.44 \mathrm{~mm}$, respectively. Only the positive control of $S$. aureus (food isolate) and $P$. aeruginosa ATCC 27853 had bigger DIZ. The rest of the controls showed lower DIZ in which $50 \%$ of honey was effective inhibiting than the antibiotic.

For $\mathrm{TH}_{2}, \mathrm{DIZ}$ was in the range of $13.91 \mathrm{~mm}$ and $27.16 \mathrm{~mm}$ as seen in Table 3 The highest DIZ was seen on $S$. aureus ATCC 29737 which was $27.26 \mathrm{~mm}$ at $50 \%$ and the lowest DIZ was seen on both $S$. enterica ser. Typhimurium ATCC 13311 and E. coli which were almost the same $13.91 \mathrm{~mm}$ and $13.93 \mathrm{~mm}$ at $12.5 \%$ and $25 \%$, respectively. In the positive control, S. aureus (food isolate) had bigger DIZ of $2.29 \mathrm{~mm}$. The rest of the controls showed lower DIZ. While for $\mathrm{AH}$, the range was between $11.17 \mathrm{~mm}$ and $33.87 \mathrm{~mm}$ as shown in Table 4, S. enterica ser. Typhimurium ATCC 13311 showed bigger DIZ than $\mathrm{TH}_{1}$, which was $33.87 \mathrm{~mm}$ followed by both $S$. aureus and S. aureus ATCC 29737, which had $26.06 \mathrm{~mm}$ and $29.73 \mathrm{~mm}$ DIZ respectively, at $50 \%$. The lowest DIZ was seen on S. enterica ser. Typhimurium ATCC 13311 same as $\mathrm{TH}_{2}$ which was $11.1 \mathrm{~mm}$ at $12.5 \%$. All positive control had smaller DIZ as compared to $50 \%$

Table 2. Diameter of inhibition zone (DIZ) of Tualang Honey $\left(\mathrm{TH}_{1}\right)$ against foodborne and pathogenic bacteria using Well Diffusion Assay

\begin{tabular}{lcccc}
\hline \multirow{2}{*}{ Bacteria } & \multicolumn{3}{c}{$\mathrm{TH}_{1}(\%)$} \\
\cline { 2 - 5 } & $12.5 \mathrm{~mm}$ & $25 \mathrm{~mm}$ & $50 \mathrm{~mm}$ & Control \\
\hline S. aureus & $6.00 \pm 0.00^{\mathrm{c}}$ & $15.82 \pm 0.57^{\mathrm{b}}$ & $23.66 \pm 0.23^{\mathrm{a}}$ & P 25.36 \\
S. aureus ATCC 29737 & $6.00 \pm 0.00^{\mathrm{b}}$ & $6.00 \pm 0.00^{\mathrm{b}}$ & $25.88 \pm 0.18^{\mathrm{a}}$ & P 22.45 \\
E. coli & $18.13 \pm 0.18^{\mathrm{b}}$ & $6.00 \pm 0.00^{\mathrm{c}}$ & $25.23 \pm 0.18^{\mathrm{a}}$ & CIP 7.47 \\
E. coli ATCC 10536 & $6.00 \pm 0.00^{\mathrm{b}}$ & $6.00 \pm 0.00^{\mathrm{b}}$ & $23.38 \pm 0.40^{\mathrm{a}}$ & CIP 7.73 \\
S. enterica ser. Typhimurium ATCC 13311 & $6.00 \pm 0.00^{\mathrm{c}}$ & $18.37 \pm 0.19^{\mathrm{b}}$ & $31.95 \pm 1.27^{\mathrm{a}}$ & CN 16.34 \\
P. aeruginosa ATCC 27853 & $6.00 \pm 0.00^{\mathrm{a}}$ & $6.00 \pm 0.00^{\mathrm{a}}$ & $6.00 \pm 0.00^{\mathrm{a}}$ & $\mathrm{CN} 12.56$ \\
C. jejuni ATCC 29428 & $6.00 \pm 0.00^{\mathrm{b}}$ & $6.00 \pm 0.00^{\mathrm{b}}$ & $25.44 \pm 0.16^{\mathrm{a}}$ & CIP 0.00 \\
L. monocytogenes ATCC 19112 & $6.00 \pm 0.00^{\mathrm{a}}$ & $6.00 \pm 0.00^{\mathrm{a}}$ & $6.00 \pm 0.00^{\mathrm{a}}$ & CIP 0.00 \\
\hline
\end{tabular}

Diameter of inhibition zone in $\mathrm{mm}$ (including disc). Values are expressed as mean \pm standard deviation. Values with different superscript within the row are significantly different $(p<0.05)$.

Table 3. Diameter of inhibition zone (DIZ) of Tualang Honey $\left(\mathrm{TH}_{2}\right)$ against foodborne and pathogenic bacteria using Well Diffusion Assay

\begin{tabular}{lcccc}
\hline \multirow{2}{*}{ Bacteria } & \multicolumn{3}{c}{$\mathrm{TH}_{2}(\%)$} \\
\cline { 2 - 5 } & $12.5 \mathrm{~mm}$ & $25 \mathrm{~mm}$ & $50 \mathrm{~mm}$ & Control \\
\hline S. aureus & $21.69 \pm 0.06^{\mathrm{c}}$ & $23.21 \pm 0.25^{\mathrm{b}}$ & $25.55 \pm 0.40^{\mathrm{a}}$ & P 27.29 \\
S. aureus ATCC 29737 & $6.00 \pm 0.00^{\mathrm{c}}$ & $20.27 \pm 0.25^{\mathrm{b}}$ & $27.16 \pm 0.86^{\mathrm{a}}$ & P 25.76 \\
E. coli & $6.00 \pm 0.00^{\mathrm{c}}$ & $13.93 \pm 0.43^{\mathrm{b}}$ & $25.12 \pm 0.44^{\mathrm{a}}$ & CIP 7.33 \\
E. coli ATCC 10536 & $21.08 \pm 0.11^{\mathrm{b}}$ & $23.60 \pm 0.85^{\mathrm{ab}}$ & $25.11 \pm 1.04^{\mathrm{a}}$ & CIP 8.10 \\
S. enterica ser. Typhimurium ATCC 13311 & $13.91 \pm 0.47^{\mathrm{c}}$ & $20.53 \pm 0.30^{\mathrm{b}}$ & $25.07 \pm 0.09^{\mathrm{a}}$ & CN 18.22 \\
P. aeruginosa ATCC 27853 & $6.00 \pm 0.00^{\mathrm{b}}$ & $6.00 \pm 0.00^{\mathrm{b}}$ & $24.64 \pm 0.81^{\mathrm{a}}$ & CN 14.32 \\
C. jejuni ATCC 29428 & $6.00 \pm 0.00^{\mathrm{b}}$ & $6.00 \pm 0.00^{\mathrm{b}}$ & $22.26 \pm 1.02^{\mathrm{a}}$ & CIP 0.00 \\
L. monocytogenes ATCC 19112 & $6.00 \pm 0.00^{\mathrm{a}}$ & $6.00 \pm 0.00^{\mathrm{a}}$ & $6.00 \pm 0.00^{\mathrm{a}}$ & CIP 0.00 \\
\hline
\end{tabular}

Diameter of inhibition zone in $\mathrm{mm}$ (including disc). Values are expressed as mean \pm standard deviation. Values with different superscript within the row are significantly different $(p<0.05)$. 
Table 4. Diameter of inhibition zone (DIZ) of Acacia Honey (AH) against foodborne and pathogenic bacteria using Well Diffusion Assay

\begin{tabular}{lcccc}
\hline \multirow{2}{*}{ Bacteria } & \multicolumn{4}{c}{ AH $(\%)$} \\
\cline { 2 - 5 } S. aureus & $12.5 \mathrm{~mm}$ & $25 \mathrm{~mm}$ & $50 \mathrm{~mm}$ & Control \\
S. aureus ATCC 29737 & $18.14 \pm 0.17^{\mathrm{b}}$ & $18.94 \pm 1.02^{\mathrm{b}}$ & $26.06 \pm 0.08^{\mathrm{a}}$ & P 23.50 \\
E. coli & $19.29 \pm 0.06^{\mathrm{c}}$ & $23.70 \pm 0.37^{\mathrm{b}}$ & $29.73 \pm 0.52^{\mathrm{a}}$ & P 27.00 \\
E. coli ATCC 10536 & $6.00 \pm 0.00^{\mathrm{c}}$ & $22.97 \pm 0.32^{\mathrm{b}}$ & $25.29 \pm 0.33^{\mathrm{a}}$ & CIP 7.44 \\
S. enterica ser. Typhimurium ATCC 13311 & $11.17 \pm 0.77^{\mathrm{c}}$ & $20.61 \pm 0.31^{\mathrm{b}}$ & $33.87 \pm 0.36^{\mathrm{a}}$ & CN 19.14 \\
P. aeruginosa ATCC 27853 & $6.00 \pm 0.00^{\mathrm{c}}$ & $21.81 \pm 0.61^{\mathrm{b}}$ & $25.08 \pm 0.60^{\mathrm{a}}$ & CIP 7.10 \\
C. jejuni ATCC 29428 & $15.86 \pm 0.45^{\mathrm{c}}$ & $21.82 \pm 0.47^{\mathrm{b}}$ & $25.15 \pm 0.88^{\mathrm{a}}$ & CN 16.50 \\
L. monocytogenes ATCC 19112 & $6.00 \pm 0.00^{\mathrm{c}}$ & $16.89 \pm 0.39^{\mathrm{b}}$ & $22.18 \pm 1.05^{\mathrm{a}}$ & CIP 0.00 \\
\hline
\end{tabular}

Diameter of inhibition zone in $\mathrm{mm}$ (including disc). Values are expressed as mean \pm standard deviation. Values with different superscript within the row are significantly different $(p<0.05)$.

Table 5. Diameter of inhibition zone (DIZ) of Yemeni Sumur Honey (YSH) against foodborne and pathogenic bacteria using Well Diffusion Assay

\begin{tabular}{lcccc}
\hline \multirow{2}{*}{ Bacteria } & \multicolumn{4}{c}{ YSH (\%) } \\
\cline { 2 - 5 } & $12.5 \mathrm{~mm}$ & $25 \mathrm{~mm}$ & $50 \mathrm{~mm}$ & Control \\
\hline S. aureus & $15.13 \pm 0.09^{\mathrm{c}}$ & $19.87 \pm 0.13^{\mathrm{b}}$ & $29.89 \pm 0.46^{\mathrm{a}}$ & P 28.11 \\
S. aureus ATCC 29737 & $6.00 \pm 0.00^{\mathrm{b}}$ & $6.00 \pm 0.00^{\mathrm{b}}$ & $35.75 \pm 0.69^{\mathrm{a}}$ & P 26.00 \\
E. coli & $6.00 \pm 0.00^{\mathrm{c}}$ & $25.19 \pm 0.63^{\mathrm{b}}$ & $27.71 \pm 0.77^{\mathrm{a}}$ & CIP 8.20 \\
E. coli ATCC 10536 & $6.00 \pm 0.00^{\mathrm{c}}$ & $22.84 \pm 0.49^{\mathrm{b}}$ & $29.01 \pm 1.30^{\mathrm{a}}$ & CIP 7.24 \\
S. enterica ser. Typhimurium ATCC 13311 & $6.00 \pm 0.00^{\mathrm{c}}$ & $20.80 \pm 0.55^{\mathrm{b}}$ & $24.99 \pm 1.15^{\mathrm{a}}$ & CN 18.26 \\
P. aeruginosa ATCC 27853 & $6.00 \pm 0.00^{\mathrm{c}}$ & $23.83 \pm 1.16^{\mathrm{a}}$ & $26.50 \pm 0.71^{\mathrm{a}}$ & CN 15.00 \\
C. jejuni ATCC 29428 & $6.00 \pm 0.00^{\mathrm{c}}$ & $17.58 \pm 0.74^{\mathrm{b}}$ & $21.96 \pm 1.30^{\mathrm{a}}$ & CIP 0.00 \\
L. monocytogenes ATCC 19112 & $6.00 \pm 0.00^{\mathrm{a}}$ & $6.00 \pm 0.00^{\mathrm{a}}$ & $6.00 \pm 0.00^{\mathrm{a}}$ & CIP 0.00 \\
\hline
\end{tabular}

Diameter of inhibition zone in $\mathrm{mm}$ (including disc). Values are expressed as mean \pm standard deviation. Values with different superscript within the row are significantly different $(p<0.05)$.

honey concentration. YSH was in a range of $15.13 \mathrm{~mm}$ and $35.75 \mathrm{~mm}$, as seen in Table 5. S. aureus ATCC 29737 showed the highest DIZ, $35.75 \mathrm{~mm}$ at $50 \%$.

Meanwhile, at $12.5 \%$, only $S$. aureus was inhibited with DIZ of $15.13 \mathrm{~mm}$, and it was the lowest DIZ. All positive control had smaller DIZ as compared to $50 \%$ honey concentration. There was no inhibition of $B$. cereus and L. monocytogenes ATCC 19112 in all four types of honey.

Agar Diffusion Assay to assess the antibacterial activity is commonly performed in three different ways; well/cup diffusion, disc diffusion or agar dilution. The method usually depends on the nature of the antibacterial or the antibacterial to be tested, and on the kinetic properties of the molecules present in the honey. Agar well allows direct contact of honey components and bacteria immediately after application. The diffusion mechanism may also represent in-vivo conditions when honey is applied on infected wounds, and therefore, may provide information about the kinetic system of honey application (Zainol et al., 2013).

Both well diffusion and disc diffusion were performed to compare between them, and there was a huge difference between the results which was obtained by both methods. Agar well exercise allows direct contact of honey components and bacteria immediately after application. In one study, it was shown that Tualang Honey could inhibit the growth of food spoilage bacteria which were $S$. aureus, $S$. enterica ser. Typhimurium, $E$. coli and P. aeruginosa as the DIZ was $24.50 \mathrm{~mm}, 18$ $\mathrm{mm}, 16.50 \mathrm{~mm}$ and $16 \mathrm{~mm}$, respectively (Aween et al., 2014). In the present work, for $\mathrm{TH}_{1}, S$. aureus had 15.82 $\mathrm{mm}$ DIZ at $25 \%$ which was less than they reported, but for $\mathrm{TH}_{2}$ it was similar to the previous study for both $S$. aureus and S. aureus ATCC 29737 with DIZ of 23.21 $\mathrm{mm}$ and $20.27 \mathrm{~mm}$. For $S$. enterica ser. Typhimurium ATCC 13311, both $\mathrm{TH}_{1}$ and $\mathrm{TH}_{2}$ had larger zones which were $18.37 \mathrm{~mm}$ and $20.53 \mathrm{~mm}$, respectively.

Several researchers have tested the antibacterial activity of honey including Acacia, Tualang, and Manuka (UMF 18+) honey using well diffusion method against $S$. aureus, E. coli, P. aeruginosa and B. cereus; The highest inhibitory zone was obtained from Manuka honey against $S$. aureus with DIZ of $19.81 \mathrm{~mm}$ and in $E$. coli $14.04 \mathrm{~mm}$. While in Tualang honey, P. aeruginosa 
showed DIZ of $16.22 \mathrm{~mm}$ and in B. cereus $27.35 \mathrm{~mm}$. Acacia honey showed the lowest inhibitory activity as compared to the other honey samples (Zainol et al., 2013). In this study, YSH showed bigger zones than Seder honey (Aween et al., 2014). Yemeni honey is well known for the antibacterial activity and the ability to fight bacteria. In $S$. enterica ser. Typhimurium ATCC 13311, the DIZ was $20.80 \mathrm{~mm}$, and in E. coli it was $25.19 \mathrm{~mm}$. In $P$. aeruginosa ATCC 27853, DIZ was $23.83 \mathrm{~mm}$, and in E. coli ATCC $1053622.84 \mathrm{~mm}$ (Aween et al., 2014). Furthermore, in this study, AH showed bigger DIZ when compared to another study which also used Acacia honey (Zainol et al., 2013). S. aureus ATCC 2937 showed DIZ of $23.70 \mathrm{~mm}$, E. coli $22.97 \mathrm{~mm}$ and $P$. aeruginosa ATCC $2785321.82 \mathrm{~mm}$. Overall in the present study, both Tualang and Acacia honey showed an inhibitory effect against $S$. aureus, $E$. coli, $P$. aeruginosa, and $S$. enterica ser. Typhimurium.

The antibacterial activity of Tetragonisca angustula honey has been well known and was found to possess good antibacterial activity against $S$. aureus. Another study revealed that $T$. angustula honey had significant antibacterial activity against several different bacterial strains, including $B$. cereus and $P$. aeruginosa (Miorin et al., 2003). A recent study has confirmed the antibacterial activity of $T$. angustula honey on Gram-positive bacteria such as $S$. aureus, and Gram-negative bacteria such as $P$. aeruginosa and E. coli (Rao et al., 2016). Wilkinson and Cavanagh (2005) studied the antibacterial activity of different types of honey against $E$. coli and $P$. aeruginosa. They found that all types of honey showed a zone of inhibition. A study was done using Nigerian honey against $S$. aureus, E. coli, and $P$. aeruginosa. It was found that $50 \%$ concentration could inhibit $P$. aeruginosa with DIZ of $8 \mathrm{~mm}$ and $100 \%$ could inhibit all the other bacteria with DIZ of $11 \mathrm{~mm}, 13.3 \mathrm{~mm}$ and 8 $\mathrm{mm}$ for $S$. aureus, E. coli and $P$. aeruginosa, respectively (Agbaje et al., 2006).

The inconsistency in the observed antibacterial activity could be due to a number of reasons. One of them could be related to the differences in susceptibility of each species of bacterium to the antibacterial activity of honey tested. Similar results were reported by Taormina et al. (2001). Furthermore, the different results observed between honey samples might also be due to the different floral sources used by the bees as well as the geographical factors like humidity, temperature, and where the honey was produced (Tumin et al., 2005). Previously, Ainul Hafiza et al. (2005) conducted a study of five types of local honey (Belimbing, Gelam, Durian, Kelapa and Tualang); using agar diffusion method for antibacterial activity against $S$. aureus. All samples had low colony counts ranging from $37 \mathrm{CFU} / \mathrm{mL}$ in Kelapa honey to $161 \mathrm{CFU} / \mathrm{mL}$ in Durian honey. All samples showed a clear zone of inhibition, and there was a significant difference $(p<0.05)$ among the samples.

Tumin et al. (2005) studied the antibacterial properties of several local Malaysian brands of honey which were Tualang, Hutan, Gelang, Pucuk Daun and Ee Feng $G u$ against six bacterial species in $20 \mu \mathrm{L} / 100$ $\mu \mathrm{L}, 40 \mu \mathrm{L} / 100 \mu \mathrm{L}, 60 \mu \mathrm{L} / 100 \mu \mathrm{L}$ and $80 \mu \mathrm{L} / 100 \mu \mathrm{L}$ concentrations. They found that Tualang honey exhibited antibacterial effect against $S$. enterica ser. Typhimurium, Streptococcus pyogenes and E. coli, with the highest activity seen against $S$. enterica ser. Typhimurium. In this finding, Tualang honey exhibited antibacterial properties against most of the bacteria with $S$. aureus, $E$. coli, and $S$. enterica ser. Typhimurium showed higher effects.

The antibacterial activity of chestnut honey at 100\% concentration against $S$. aureus and E. coli were higher when compared to the flower honey at the same concentration. At $50 \%$ concentration, only chestnut honey had average inhibition against $S$. aureus. At $25 \%$ concentration, both of the honey had a slight inhibition against $S$. aureus. The diversity of flowers affect the composition of the honey produced. According to the literature, $S$. aureus is considered to be the most sensitive bacterium towards chestnut honey (Güneş et al., 2017). In the present work, all types of honey inhibited $S$. aureus and E. coli especially Tualang honey as it is well known for its antibacterial activity against $S$. aureus. Estevinho et al. (2008) studied the antibacterial activity of 20 honey samples from the nectar of Lavandula, Echium and Erica plants, and concluded that $S$. aureus was the most affected bacterium, followed by B. subtilis, $S$. lentus, K. pneumoniae and E. coli which were affected gradually.

Silici et al. (2010) examined the antibacterial activity of Rhododendron honey at concentrations of 10, 25, 50 and $75 \%$ against 13 different microorganisms. $P$. aeruginosa and $P$. mirabilis were the most sensitive microorganisms followed by $S$. aureus, Aeromonas hydrophila, L. monocytogenes, B. subtilis, Mycobacterium smegmatis, and $S$. enterica ser. Typhimurium while B. cereus, E. coli O157: $\mathrm{H} 7$ and $Y$. enterocolitica were resistant, and they did not show any DIZ. In this study, S. aureus, E. coli, S. enterica ser. Typhimurium and $P$. aeruginosa were inhibited by all types of honey, but Tualang and Yemeni Sumur honey showed higher effects. In another study, Nzeako and Hamdi (2000) investigated the antibacterial activity of six different honey samples in which Turkish honey showed higher antibacterial activity against $S$. aureus. 
3.3 Minimum Inhibitory Concentration (MIC) and Minimum Bactericidal Concentration (MBC) of honey samples

The disc and well diffusion methods are primarily a qualitative test for detecting the susceptibility of bacteria to antibacterial substances. However, both the MIC (the lowest concentration of the sample that will prevent at least $99 \%$ of the bacterial growth) and the MBC (the lowest concentration of honey required to kill at least $99 \%$ of the bacteria) reflects the quantity needed for bacterial inhibition (Balouiri et al., 2016). The MIC and MBC of the four types of honey are shown in Tables 6 and $7 . \mathrm{TH}_{1}$ and $\mathrm{YSH}$ had the most bacteriostatic effect as compared to other honey. They showed almost the same inhibitory concentration except for $P$. aeruginosa ATCC 27853 , which was higher in $\mathrm{TH}_{1} 12.5 \%$ MIC instead of $25 \%$ in YSH. In $\mathrm{TH}_{2}$, only $S$. aureus ATCC 29737, $S$. enterica ser. Typhimurium ATCC 13311, S. aureus (food isolate) and L. monocytogenes ATCC 1112 had $25 \%$ MIC. The rest of the bacteria did not show any inhibitory in the range which was developed. Also in $\mathrm{AH}$ only $S$. aureus ATCC 29737, S. enterica ser. Typhimurium ATCC 13311, S. aureus (food isolate) and $P$. aeruginosa ATCC 27853 showed a MIC of $25 \%$, the rest of other bacteria exceeded the range.
A previous study which used Malaysian Tualang honey showed antibacterial activity against foodborne pathogen and food spoilage bacteria. The results were as follows; S. aureus, E. coli, P. aeruginosa and S. enterica ser. Typhimurium with a MIC of 12.5, 25, 12.5 and $3.125 \%$, respectively (Shehu et al., 2015). The result was in line with this study except for $S$. enterica ser. Typhimurium, which had a lower MIC. It was also supported by Tan et al. (2009) who reported that Tualang honey exhibited lower MIC against different microorganisms.

Tualang honey closely resembled New Zealand Manuka honey (Comvita UMF 18+) as found by a study in which Malaysian honey was used as a comparison (Zainol et al., 2013). In that study the MIC of $S$. aureus was $10 \%$, E. coli $20 \%$ and $P$. aeruginosa $12.5 \%$ for both Tualang and Manuka honey. Except for B. cereus, Manuka had a lower MIC of $10 \%$ and $15 \%$ for Tualang honey. While Kelulut honey also demonstrated constant MIC and MBC results at $20 \%$ for S. aureus, E. coli, $P$. aeruginosa and B. cereus (Zainol et al., 2013).

The antibacterial activity of Tualang honey and Manuka honey was compared against the enteric microorganisms with $S$. enterica ser. Typhimurium having the highest MIC of $15 \%$, and $P$. aeruginosa, $S$.

Table 6. Minimum Inhibitory Concentration (MIC) of Tualang Honey $\left(\mathrm{TH}_{1}\right)$, Tualang Honey $\left(\mathrm{TH}_{2}\right)$, Acacia Honey $(\mathrm{AH})$ and Yemeni Sumur Honey (YSH) against foodborne and pathogenic bacteria

\begin{tabular}{lcccc}
\hline \multirow{2}{*}{\multicolumn{1}{c}{ Bacteria }} & \multicolumn{3}{c}{ Types of honey (v/v) } \\
\cline { 2 - 5 } & $\mathrm{TH}_{1}$ & $\mathrm{TH}_{2}$ & $\mathrm{AH}$ & $\mathrm{YSH}$ \\
\hline S. aureus & $12.50 \%$ & $25 \%$ & $25 \%$ & $12.50 \%$ \\
S. aureus ATCC 29737 & $12.50 \%$ & $25 \%$ & $25 \%$ & $12.50 \%$ \\
E. coli & $25 \%$ & $>50 \%$ & $>50 \%$ & $25 \%$ \\
E. coli ATCC 10536 & $25 \%$ & $>50 \%$ & $>50 \%$ & $25 \%$ \\
S. enterica ser. Typhimurium ATCC 13311 & $12.50 \%$ & $25 \%$ & $25 \%$ & $12.50 \%$ \\
P. aeruginosa ATCC 27853 & $12.50 \%$ & $>50 \%$ & $25 \%$ & $25 \%$ \\
L. monocytogenes ATCC19112 & $25 \%$ & $25 \%$ & $>50 \%$ & $25 \%$ \\
C. jejuni ATCC 29428 & $>50 \%$ & $>50 \%$ & $>50 \%$ & $>50 \%$ \\
B. cereus & $>50 \%$ & $>50 \%$ & $>50 \%$ & $>50 \%$ \\
\hline
\end{tabular}

Table 7. Minimum Bactericidal Concentration $(\mathrm{MBC})$ of Tualang Honey $\left(\mathrm{TH}_{1}\right)$, Tualang Honey $\left(\mathrm{TH}_{2}\right)$, Acacia Honey $(\mathrm{AH})$ and Yemeni Sumur Honey (YSH) against foodborne and pathogenic bacteria

\begin{tabular}{lcccc}
\hline \multirow{2}{*}{\multicolumn{1}{c}{ Bacteria }} & \multicolumn{3}{c}{ Types of honey (v/v) } \\
\cline { 2 - 5 } & $\mathrm{TH}_{1}$ & $\mathrm{TH}_{2}$ & $\mathrm{AH}$ & $\mathrm{YSH}$ \\
\hline S. aureus & $25 \%$ & $50 \%$ & $50 \%$ & $25 \%$ \\
S. aureus ATCC 29737 & $25 \%$ & $50 \%$ & $50 \%$ & $25 \%$ \\
E. coli & $50 \%$ & $>50 \%$ & $>50 \%$ & $50 \%$ \\
E. coli ATCC 10536 & $50 \%$ & $>50 \%$ & $>50 \%$ & $50 \%$ \\
S. enterica ser. Typhimurium ATCC 13311 & $25 \%$ & $50 \%$ & $50 \%$ & $25 \%$ \\
P. aeruginosa ATCC 27853 & $25 \%$ & $>50 \%$ & $50 \%$ & $50 \%$ \\
L. monocytogenes ATCC19112 & $50 \%$ & $50 \%$ & $>50 \%$ & $50 \%$ \\
C. jejuni ATCC 29428 & $>50 \%$ & $>50 \%$ & $>50 \%$ & $>50 \%$ \\
B. cereus & $>50 \%$ & $>50 \%$ & $>50 \%$ & $>50 \%$ \\
\hline
\end{tabular}


aureus and E. coli of $17.5 \%, 20 \%$ and $22.5 \%$, respectively (Tan et al., 2009). The antibacterial activity of different botanical and floral honey was studied against $S$. aureus ATCC 43300, S. aureus ATCC 25923 and $P$. aeruginosa ATCC 27853 with Manuka honey having MIC of $7 \%, 6 \%$ and $14 \%$, Acacia $10 \%, 12 \%$ and $13 \%$, lavender $25 \%, 25 \%$, and $21 \%$, and for wild carrot honey $11 \%, 13 \%$ and $12 \%$, respectively (Alzahrani et al., 2012).

$\mathrm{TH}_{1}$ and $\mathrm{YSH}$ had the most bactericidal effect compared to other honey. These two honey showed almost the same inhibitory concentration except for $P$. aeruginosa ATCC 27853, which was higher in $\mathrm{TH}_{1} 25 \%$ MBC instead of $50 \%$ in YSH. In $\mathrm{TH}_{2}$, only $S$. aureus ATCC 29737, S. enterica ser. Typhimurium ATCC 13311, S. aureus and L. monocytogenes ATCC 19112 showed MBC of $50 \%$. In contrast, the rest of the bacteria did not show any bactericidal effect in the range which was developed. Also in AH only S. aureus ATCC 29737, S. enterica ser. Typhimurium ATCC 13311, S. aureus and $P$. aeruginosa ATCC 27853 showed an MBC of $50 \%$, while the rest of the bacteria exceeded the range. Malaysian Tualang honey showed antibacterial activity against $S$. aureus, E. coli, $P$. aeruginosa and $S$. enterica ser. Typhimurium with MBC of 25, 50, 25 and 12.5, respectively (Shehu et al., 2015). The results were in line with this study except for S. enterica ser. Typhimurium, which had lower MBC. The reaction of each bacterium towards honey is different depending on the bacterial growth and also the active compounds which are present in the honey.

In another study, Tualang honey had the same effect as Manuka honey (Comvita UMF $18+$ ) against $S$. aureus, $P$. aeruginosa and $E$. coli with 15,20 and $25 \% \mathrm{MBC}$. In B. cereus, Manuka honey showed lower MBC of $12.5 \%$. In Acacia honey, $S$. aureus and B. cereus had the same MBC which was $25 \%$, and $E$. coli and $P$. aeruginosa also had the same MBC of 50\% (Zainol et al., 2013). Earlier in 2009, the effect of Tualang and Manuka honey was also studied against enteric microorganisms such as $S$. aureus and $E$. coli ( $>25 \% \mathrm{MBC}), P$. aeruginosa $(25 \%$ $\mathrm{MBC})$ and $S$. enterica ser. Typhimurium (20\% MBC) (Tan et al., 2009).

\subsection{Time-Kill}

Time-Kill Kinetics test, also known as the "suspension tests or suspension time-kill analysis", determines the time required by the antibacterial agent to kill the challenged test microorganism. This test is utilised in microbiological studies to assess a test article's in vitro antibacterial activity in relation to time. In $\mathrm{TH}_{1}$, $S$. aureus (food isolate) (Figure 1) and $S$. aureus ATCC 29737 (Figure 2) showed 4.01 and $4.83 \log \mathrm{CFU} / \mathrm{g}$ at $4 \mathrm{~h}$ in 1× MIC. After $6 \mathrm{~h}, S$. aureus (food isolate) showed complete inhibition and $3.84 \mathrm{log} \mathrm{CFU} / \mathrm{g}$ for $S$. aureus ATCC 29737 at $2 \times$ MIC. After 6 h, E. coli (food isolate), E. coli ATCC 10536, L. monocytogenes ATCC 19112 showed 5.28, 5.34 and $5.03 \log \mathrm{CFU} / \mathrm{g}$ at $1 \times$ MIC while for $S$. enterica ser. Typhimurium ATCC 1331, $P$. aeruginosa ATCC 27853 it was 4.46 and $4.30 \log$ CFU/g at $2 \times$ MIC, respectively. For $\mathrm{TH}_{2}, S$. aureus (food isolate), $S$. aureus ATCC 29737, S. enterica ser. Typhimurium ATCC 13311, $P$. aeruginosa ATCC 27853 and L. monocytogenes ATCC 19112 were 5.25, $5.28,4.38,4.18$ and $6.09 \log \mathrm{CFU} / \mathrm{g}$ in $1 \times \mathrm{MIC}$ concentration after 6 hrs, respectively. For AH, S. aureus (food isolate), S. aureus ATCC 29737 and S. enterica ser. Typhimurium ATCC 13311 showed 5.10, 5.18 and $5.53 \log$ CFU/g in $1 \times$ MIC after 6 hrs. In YSH, S. aureus (food isolate), S. aureus ATCC 29737 and S. enterica ser. Typhimurium ATCC 13311 in $2 \times$ MIC showed 4.26, 3.68 and $3.83 \log \mathrm{CFU} / \mathrm{g}$ after $6 \mathrm{~h}$ while $E$. coli (food isolate), E. coli ATCC 10536, P. aeruginosa ATCC 27853 and L. monocytogenes ATCC 19112 in $1 \times$ MIC showed 5.22, 4.80, 4.18 and $5.75 \log$ CFU/g after $6 \mathrm{hrs}$.

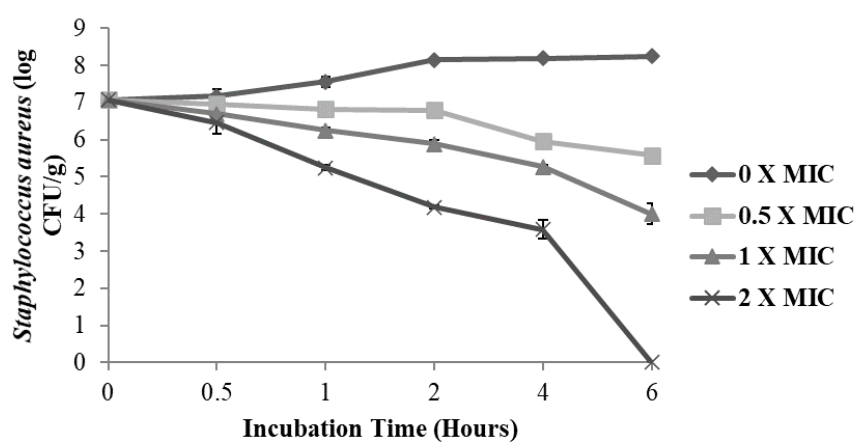

Figure 1. Time-kill plot of Tualang Honey $\left(\mathrm{TH}_{1}\right)$ against $S$. aureus

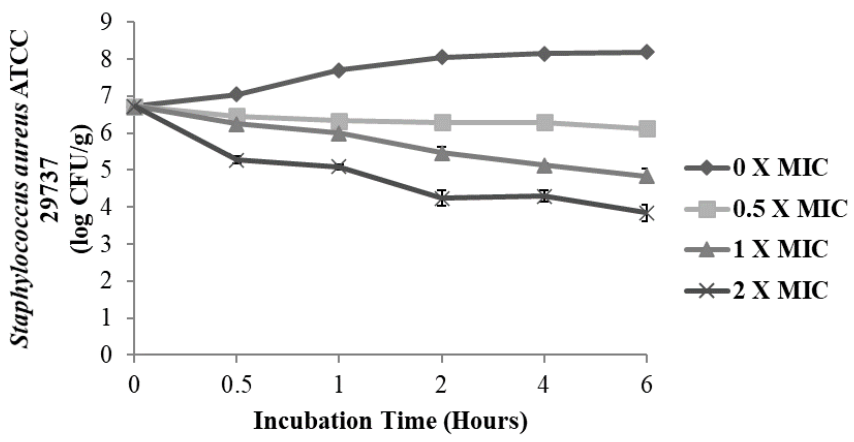

Figure 2. Time-kill plot of Tualang Honey (TH1) against $S$. aureus ATCC 29737

In one study, the growth of methicillin-resistant $S$. aureus (MRSA49) was entirely inhibited by $50 \%$ honey concentration after $8 \mathrm{hrs}$, whereas the growth of $S$. aureus was inhibited after $20 \mathrm{hrs}$. The examination of the killing kinetic of honey collected from the longan (Dimocarpus longan) flower at a concentration of $50 \%$ $(\mathrm{v} / \mathrm{v})$ showed a reduction in the survival of MRSA49 and 
$S$. aureus, although, $S$. aureus showed more resistance to honey. Therefore, the potent activity of Thai honey against antibiotic-resistant pathogenic bacteria, MRSA, was the significant finding of that study (Jantakee and Tragoolpua, 2015). The antibacterial activity of honey is a property that is of significant interest in its function as an agent in treating bacterial infections that are resistant to the action of antibiotics.

By using the time-kill test, treatment with all stingless bee honey showed a significant reduction in viability of $S$. aureus $(p<0.001)$ and $P$. aeruginosa $(p<$ 0.001 ), with a reduction in viability after 60 mins in the order of 1 to $3 \log$ and $>3 \log$ for each bacteria, respectively (Boorn et al., 2010). Moreover, results showed that stingless bee honey had a relatively rapid bactericidal action while the Apis mellifera honey did not. A previous study reported a similar trend where a little effect was seen after treatment with $25 \%$ (w/v) $A$. mellifera honey, whereas notable cell death was seen after treatment with $25 \%$ Trigona biroi honey. Although the majority of results showed clear overall trends, there were a few instances where outcomes were untypical.

The majority of constituents in a ripen honey are sugars accounting for $80 \%$ of the components which include glucose and fructose, sucrose and maltose are in a lesser amount, and less than $18 \%$ of water. The large percentages of sugars and low moisture content results in osmotic stress, hence, prevent the spoilage of honey by microorganisms. It has been observed that a slight increase in moisture content can result in yeast growth. However, the high percentage of sugar still prevents bacterial growth even after the honey is diluted to approximately 30 to $40 \%$ (Kwakman and Zaat, 2012). It is noteworthy that the antibacterial activity of honey after dilutions is due to other compounds found in honey, among which is the hydrogen peroxide $\left(\mathrm{H}_{2} \mathrm{O}_{2}\right)$. The production of $\mathrm{H}_{2} \mathrm{O}_{2}$ is catalysed by a glucose oxidase enzyme, which is incorporated into collected nectar by the honey bees during honey production. Upon adequate dilution of honey, this enzyme is activated and in turn, catalyses the conversion of glucose to $\mathrm{H}_{2} \mathrm{O}_{2}$ and gluconic acid in the presence of $\mathrm{H}_{2} \mathrm{O}$ (Kwakman and Zaat 2012).

Although $\mathrm{H}_{2} \mathrm{O}_{2}$ is the major antibacterial compound in honey, there are many honey varieties that have significant antibacterial activity resulting from nonperoxide compounds. Methylglyoxal and bee defensin-1 has been recently identified in Manuka honey and RS respectively as non-peroxide antibacterial compounds (Kwakman and Zaat 2012). The role of low pH (3.2 to 4.5) for the antibacterial activity of honey has been debatable in the world of science with a number of studies reporting opposing results with regards to the antibacterial contribution of low $\mathrm{pH}$ (Adams et al., 2008). Furthermore, studies have suggested the presence of additional unknown antibacterial compounds in honey.

\subsection{Physicochemical analysis}

\subsubsection{Determination of $p H$}

Overall, the $\mathrm{pH}$ values of the honey samples in this study were acidic ranging between 3.69 to 3.94 and within the recommended limit $\mathrm{pH}(3.4$ to 6.1) (Moniruzzaman et al., 2013) as shown in (Figure 3). AH was the most acidic honey (pH 3.69), and the least acidic honey was YSH with $\mathrm{pH}$ 3.94. $\mathrm{TH}_{2}$ and $\mathrm{TH}_{1}$ had $\mathrm{pH}$ of 3.72 and 3.91, respectively. There was a significant difference $(p<0.05)$ between the samples. Although honey is considered to be acidic, however, the high sugar content masks the acidity in the honey taste. The average $\mathrm{pH}$ of honey is $\mathrm{pH}$ 3.9. Formic acid and citric acid were originally believed to be the dominant acidic compounds in honey (Ball, 2007). However, it was recently discovered that gluconic acid is the predominant acid compound in honey, which is produced from bee secretions under the action of oxidase enzyme on glucose.

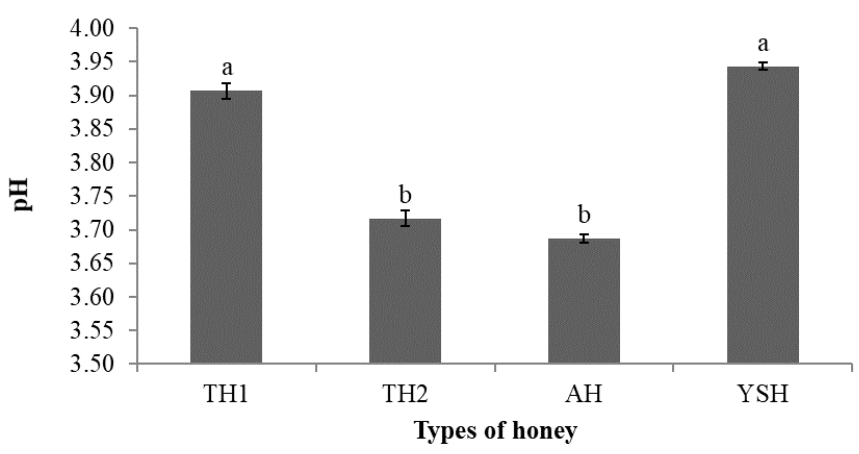

Figure 3. $\mathrm{pH}$ values of Tualang Honey $\left(\mathrm{TH}_{1}\right)$, Tualang Honey $\left(\mathrm{TH}_{2}\right)$, Acacia Honey $(\mathrm{AH})$ and Yemeni Sumur Honey (YSH). Bars with different letters are significantly different $(p<0.05)$.

A variation in the $\mathrm{pH}$ values of Brazilian, Spanish, Turkish and Algerian honey was found to be in the range of 3.10 to $4.05,3.63$ to $5.01,3.67$ to 4.57 and 3.49 to 4.53 respectively (Amri and Ladjama, 2013). A pH value between 3.5 to 5.0 for honey from Northwest Spain was also reported (Olga et al., 2012). Similarly, $\mathrm{pH}$ values between 3.8 to 4.5 for Moroccan honey were also reported (Karabagias et al., 2014). The acidity is likely to contribute to the antibacterial potency of the honey (Almasaudi et al., 2016). Properties and the composition of honey depend on its geographical floral origin, season, environmental factors as well as treatment of beekeepers (El Sohaimy et al., 2015).

\subsubsection{Determination of water activity}

The water activity $\left(a_{w}\right)$ of honey samples were in 
between 0.53 to 0.62 (Figure 4). The $\mathrm{a}_{\mathrm{w}}$ of honey should be below 0.60 (Chirife et al., 2006). $\mathrm{TH}_{2}$ exceeded the level with $0.62 \mathrm{a}_{\mathrm{w}}$; the rest of the honey was within the limit. $\mathrm{TH}_{1}$ and $\mathrm{YSH}$ had the same $\mathrm{a}_{\mathrm{w}}$ of 0.53 , and for $\mathrm{AH}$ it was 0.60 . There was a significant difference $(p<0.05)$ in $\mathrm{a}_{\mathrm{w}}$ between the samples. These results are quite similar to those of Greek honey for which the $\mathrm{a}_{\mathrm{w}}$ ranged from 0.53 to 0.67 (Lazaridou et al., 2004). The $\mathrm{a}_{\mathrm{w}}$ is an important factor which governs the food stability by preventing or limiting microbial growth. The increase in $\mathrm{a}_{\mathrm{w}}$ influences the shelf life of honey and supports the growth of undesirable microflora, especially osmotolerant yeasts. The osmotolerant yeasts are able to grow at a minimal $\mathrm{a}_{\mathrm{w}}$ of 0.60 (Saxena et al., 2010). Although osmolality plays a significant role in the antibacterial activity of honey, there are other factors that influence the antibacterial effect of honey. The presence of such factors in honey depends to a greater extent on the source of nectar, location of the flowers, the storage time, preservation method and related water conditions (Almasaudi et al., 2016). Some of the quality problems found in honey such as stability, viscosity and crystallisation are due to $\mathrm{a}_{\mathrm{w}}$ (Zamora et al., 2006). During glucose crystallisation, glucose monohydrate is formed, and other water molecules are dehydrated, resulting in a decrease in solute concentration in the liquid phase and increase in $\mathrm{a}_{\mathrm{w}}$.

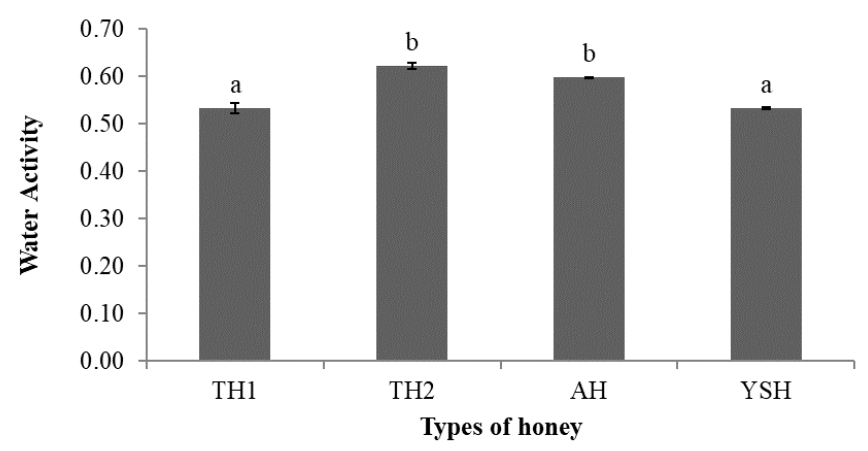

Figure 4. Water activities of Tualang Honey $\left(\mathrm{TH}_{1}\right)$, Tualang Honey $\left(\mathrm{TH}_{2}\right)$, Acacia Honey (AH) and Yemeni Sumur Honey $(\mathrm{YSH})$. Bars with different letters are significantly different $(p$ $<0.05)$.

\subsubsection{Colour analysis}

Colour is the first attractive attribute of honey, and as such, it is very important for commercialisation. It is a significant parameter in the quality, acceptance and preference of consumers (Missio et al., 2016). As shown in Table 8, the $\mathrm{L}^{*}$ parameter ranged from 2.27 to 13.63 . The $\mathrm{a}^{*}$ parameter ranged between 1.44 to 1.62 . The $\mathrm{b}^{*}$ parameter ranged from 12.09 to 2.27 . There was a significant $(p<0.05)$ difference between the samples. The maximum and minimum lightness was seen in YSH and $\mathrm{AH}$, respectively. The maximum and minimum redness was seen in $\mathrm{TH}_{1}$ and $\mathrm{AH}$, respectively. The maximum and minimum brightness was seen in YSH and $\mathrm{AH}$, respectively. Honey's colour normally differs over a wide range of tones, ranging from light yellow to amber, dark amber and, in rare cases, black. Occasionally, even green or red hues may occur.

The colour of unprocessed honey depends on its botanical or floral origins. For this reason, colour is significant in the classification of monofloral honey for commercial activities (Moniruzzaman et al., 2013). It also depends on its ash content, temperature and time of storage (Gámbaro et al., 2006). The Codex Alimentarius Committee on Sugars (2001) stipulates that the colour of honey should be nearly colourless to dark brown. In one study, seven reputed commercial Indian honey brands showed $\mathrm{L}^{*}, \mathrm{a}^{*}$ and $\mathrm{b}^{*}$ values ranging from 26.3 to 36.8 , 0.12 to 4.9 and 0.7 to 14.4 , respectively (Saxena et al., 2010). Boussaid et al. (2014) evaluated six samples of honey which were collected from different regions of Tunisia and found that $L^{*}$ values ranged from 36.64 to 51.37. The lightness of honey plays an important role as it is what the consumers prefer. The analysed honey also contains other colours orange, green and yellow. Rosemary honey showed green colour, which is the negative value of $a^{*}$ while mint honey had the highest redness followed by eucalyptus honey. The orange, thyme eucalyptus horehound and mint honey showed values between 10 and 20 for $\mathrm{b}^{*}$ (Boussaid et al., 2014).

Table 8. Color analysis of Tualang Honey $\left(\mathrm{TH}_{1}\right)$, Tualang Honey $\left(\mathrm{TH}_{2}\right)$, Acacia Honey (AH) and Yemeni Sumur Honey (YSH)

\begin{tabular}{cccc}
\hline Honey & $\mathrm{L}^{*}$ & $\mathrm{a}^{*}$ & $\mathrm{~b}^{*}$ \\
\hline $\mathrm{TH}_{1}$ & $3.93 \pm 0.62^{\mathrm{b}}$ & $1.62 \pm 0.17^{\mathrm{a}}$ & $2.61 \pm 0.10^{\mathrm{b}}$ \\
$\mathrm{TH}_{2}$ & $2.97 \pm 0.21^{\mathrm{b}}$ & $1.58 \pm 0.12^{\mathrm{a}}$ & $3.16 \pm 0.07^{\mathrm{b}}$ \\
$\mathrm{AH}$ & $2.27 \pm 0.04^{\mathrm{b}}$ & $1.44 \pm 0.09^{\mathrm{a}}$ & $2.27 \pm 0.05^{\mathrm{b}}$ \\
$\mathrm{YSH}$ & $13.63 \pm 0.54^{\mathrm{a}}$ & $1.52 \pm 0.10^{\mathrm{a}}$ & $12.09 \pm 0.62^{\mathrm{a}}$ \\
\hline
\end{tabular}

Diameter of inhibition zone in mm (including disc). Values are expressed as mean \pm standard deviation. Values with different superscript within the row are significantly different $(p<$ $0.05)$.

\section{Conclusion}

In disc diffusion, $\mathrm{TH}_{1}$ and $\mathrm{YSH}$ showed higher DIZ of $10.08 \mathrm{~mm}$ and $12.49 \mathrm{~mm}$ at $25 \%$, and $15.01 \mathrm{~mm}$ and $20.35 \mathrm{~mm}$ at $50 \%$ against $S$. aureus (food isolate), respectively. While in well diffusion, $\mathrm{TH}_{1}$ and $\mathrm{AH}$ showed the highest DIZ of $31.95 \mathrm{~mm}$ and $33.87 \mathrm{~mm}$ by S. enterica ser. Typhimurium ATCC 13311 at 50\%. Meanwhile, in $\mathrm{TH}_{2}$ and YSH, S. aureus ATCC 29737 showed the highest DIZ of $27.16 \mathrm{~mm}$ and $35.75 \mathrm{~mm}$ at $50 \%$. In $\mathrm{TH}_{1}$, positive control of $S$. aureus (food isolate) and $P$. aeruginosa ATCC 27853 showed bigger DIZ than $50 \%$ honey concentration while $\mathrm{TH}_{2}$ on $S$. aureus (food isolate) positive control had bigger DIZ. In both $\mathrm{AH}$ and 
YSH, $50 \%$ of honey had bigger DIZ than the positive control. The lowest MIC was obtained by both $\mathrm{TH}_{1}$ and YSH against $S$. aureus (food isolate), S. aureus ATCC 29737, P. aeruginosa ATCC 27853 and S. enterica ser. Typhimurium ATCC 13311 with $12.5 \%$ MIC concentration, and the lowest $\mathrm{MBC}$ was also by $\mathrm{TH}_{1}$ and YSH against $S$. aureus (food isolate), $S$. aureus ATCC 29737 and S. enterica ser. Typhimurium ATCC 13311 with $25 \% \mathrm{MBC}$ concentration. In the time-kill test, $\mathrm{TH}_{1}$ on $S$. aureus (food isolate) showed a complete reduction at $6 \mathrm{hrs}$ and in $\mathrm{TH}_{2}$ on $S$. enterica ser. Typhimurium ATCC 13311 showed the highest reduction of $2.21 \mathrm{log}$ $\mathrm{CFU} / \mathrm{g}$ at $1 \times$ MIC. For AH, $P$. aeruginosa ATCC 27853 showed the highest reduction of $2.48 \log \mathrm{CFU} / \mathrm{g}$ at $1 \times$ MIC, and for YSH, S. aureus (food isolate) and $S$. enterica ser. Typhimurium ATCC 13311 showed 2.74 and $2.73 \log \mathrm{CFU} / \mathrm{g}$ at $2 \times \mathrm{MIC}$, respectively. The highly acidic honey was $\mathrm{AH}$ with $\mathrm{pH}$ of 3.69, and the lowest water activity was measured in $\mathrm{TH}_{1}$ and $\mathrm{YSH}$ at 0.53 . Maximum $\mathrm{L}^{*}$ and $\mathrm{b}^{*}$ was by $\mathrm{YSH}$, and maximum $\mathrm{a}^{*}$ was by $\mathrm{TH}_{1}$.

\section{Conflict interests}

The authors declare that they have no competing interests.

\section{Acknowledgement}

We gratefully acknowledge the financial support from Universiti Putra Malaysia under IPS (Insentif Putra Siswazah) Research Grant (GP-IPS/2016/9488200).

\section{References}

Adams, C.J., Boult, C.H., Deadman, B.J., Farr, J.M., Grainger, M.N., Manley-Harris, M. and Snow, M.J. (2008). Isolation by HPLC and characterisation of the bioactive fraction of New Zealand manuka (Leptospermum scoparium) honey. Carbohydrate Research, 343(4), 651-659. https://doi.org/10.1016/ j.carres.2007.12.011

Agbaje, E.O., Ogunsanya, T. and Aiwerioba, O.I.R. (2006). Conventional use of honey as antibacterial agent. Annals of African Medicine, 5(2), 78-81.

Ainul Hafiza, A.H., Yusof, N. and Maimon, A. (2005). Potential of Malaysian local honey as an antibacterial agent. Sains Malaysiana, 34(1), 17-20.

Almasaudi, S.B., Al-nahari, A.A.M., El-ghany, E.S.M.A., Muhayawi, S.M.A., Al-jaouni, S., Azhar, E. and Harakeh, S. (2017). Antimicrobial effect of different types of honey on Staphylococcus aureus. Saudi Journal of Biological Sciences, 24(6), 12551261. https://doi.org/10.1016/j.sjbs.2016.08.007

Alzahrani, H.A., Alsabehi, R., Boukraâ, L., Abdellah,
F., Bellik, Y. and Bakhotmah, B.A. (2012). Antibacterial and antioxidant potency of floral honeys from different botanical and geographical origins. Molecules, 17(9), 10540-10549. https:// doi.org/10.3390/molecules170910540

Amri, A. and Ladjama, A. (2013). Physicochemical characterisation of some multifloral honeys from honeybees Apis mellifera collected in the Algerian northeast. African Journal of Food Science, 7(7), 168-173. https://doi.org/10.5897/AJFS13.0986

Aween, M.M., Hassan, Z., Huda-Faujani, N., Emdakim, M.M. and Muhialdin, B.J. (2014). Potency of honey as antibacterial agent against multiple antibiotic resistant pathogens evaluated by different methods. American Journal of Applied Sciences, 11(10), 1773 -1783. https://doi.org/10.3844/ofsp.9491

Ball, D.W. (2007). The chemical composition of honey. Journal of Chemical Education, 84(10), 1643. https://doi.org/10.1021/ed084p1643

Balouiri, M., Sadiki, M. and Ibnsouda, S.K. (2016). Methods for in vitro evaluating antimicrobial activity: A review. Journal of Pharmaceutical Analysis, 6(2), 71-79. https://doi.org/10.1016/ j.jpha.2015.11.005

Boorn, K.L., Khor, Y.Y., Sweetman, E., Tan, F., Heard, T.A. and Hammer, K.A. (2010). Antimicrobial activity of honey from the stingless bee Trigona carbonaria determined by agar diffusion, agar dilution, broth microdilution and time-kill methodology. Journal of Applied Microbiology, 108 (5), 1534-1543. https://doi.org/10.1111/j.13652672.2009.04552.x

Boukraâ, L. (Ed.). (2013). Honey in traditional and modern medicine. USA: CRC Press. https:// doi.org/10.1201/b15608

Boussaid, A., Chouaibi, M., Rezig, L., Hellal, R., Donsì, F., Ferrari, G. and Hamdi, S. (2018). Physicochemical and bioactive properties of six honey samples from various floral origins from Tunisia. Arabian Journal of Chemistry, 11(2), 265274. https://doi.org/10.1016/j.arabjc.2014.08.011

Chirife, J., Zamora, M.C. and Motto, A. (2006). The correlation between water activity and $\%$ moisture in honey: Fundamental aspects and application to Argentine honeys. Journal of Food Engineering, 72 (3), 287-292. https://doi.org/10.1016/ j.jfoodeng.2004.12.009

Codex Alimentarius Committee. (2001). Codex Alimentarius Committee on Sugars 2001. Rome: FAO. Retrieved from www.fao.org/input/download/ standards/338/CXS_212e_u.pdf.

El Sohaimy, S.A., Masry, S.H.D. and Shehata, M.G. 
(2015). Physicochemical characteristics of honey from different origins. Annals of Agricultural Sciences, 60(2), 279-287. https://doi.org/10.1016/ j.aoas.2015.10.015

Estevinho, L., Pereira, A.P., Moreira, L., Dias, L.G. and Pereira, E. (2008). Antioxidant and antimicrobial effects of phenolic compounds extracts of Northeast Portugal honey. Food and Chemical Toxicology, 46 (12), 3774-3779. https://doi.org/10.1016/ j.fct.2008.09.062

Güneş, M.E., Şahin, S., Demir, C., Borum, E. and Tosunoğlu, A. (2017). Determination of phenolic compounds profile in chestnut and floral honeys and their antioxidant and antimicrobial activities. Journal of Food Biochemistry, 41(3), 12345. https://doi.org/10.1111/jfbc.12345

Jantakee, K. and Tragoolpua, Y. (2015). Activities of different types of Thai honey on pathogenic bacteria causing skin diseases, tyrosinase enzyme and generating free radicals. Biological Research, 48(1), 4. https://doi.org/10.1186/0717-6287-48-4

Karabagias, I.K., Badeka, A., Kontakos, S., Karabournioti, S. and Kontominas, M.G. (2014). Characterisation and classification of Greek pine honeys according to their geographical origin based on volatiles, physicochemical parameters and chemometrics. Food Chemistry, 146, 548-557. https://doi.org/10.1016/j.foodchem.2013.09.105

Kwakman, P.H. and Zaat, S.A. (2012). Antibacterial components of honey. IUBMB Life, 64(1), 48-55. https://doi.org/10.1002/iub.578

Lazaridou, A., Biliaderis, C.G., Bacandritsos, N. and Sabatini, A. G. (2004). Composition, thermal and rheological behaviour of selected Greek honeys. Journal of Food Engineering, 64(1), 9-21. https:// doi.org/10.1016/j.jfoodeng.2003.09.007

Miorin, P.L., Levy Junior, N.C., Custodio, A.R., Bretz, W.A. and Marcucci, M.C. (2003). Antibacterial activity of honey and propolis from Apis mellifera and Tetragonisca angustula against Staphylococcus aureus. Journal of Applied Microbiology, 95(5), 913 -920 . https://doi.org/10.1046/j.13652672.2003.02050.x

Missio, P., Gauche, C., Gonzaga, L.V., Carolina, A. and Costa, O. (2016). Honey: Chemical composition, stability and authenticity. Food Chemistry, 196, 309 -323 . https://doi.org/10.1016/ j.foodchem.2015.09.051

Moniruzzaman, M., Khalil, M.I., Sulaiman, S.A. and Gan, S.H. (2013) Physicochemical and antioxidant properties of Malaysian honeys produced by Apis cerana, Apis dorsata and Apis mellifera. BMC
Complementary and Alternative Medicine, 13(1), 43. https://doi.org/10.1186/1472-6882-13-43

Nzeako, B.C. and Hamdi, J. (2000). Antimicrobial potential of honey on some microbial isolates. Sultan Qaboos University Medical Journal, 2(2), 75-79.

Olga, E., María, F.G. and Carmen, S.M. (2012). Differentiation of blossom honey and honeydew honey from Northwest Spain. Agricultural, 2(1), 2537. https://doi.org/10.3390/agriculture2010025

Rao, P.V., Krishnan, K.T., Salleh, N. and Gan, S.H. (2016). Biological and therapeutic effects of honey produced by honey bees and stingless bees: a comparative review. The Brazilian Journal of Pharmaceutical Sciences, 26(5), 657-664. https:// doi.org/10.1016/j.bjp.2016.01.012

Rukayadi, Y., Han, S., Yong, D. and Hwang, J.K. (2010). In vitro antibacterial activity of panduratin A against enterococci clinical isolates. Biology and Pharmaceutical Bulletin, 33(9), 1489-1493. https:// doi.org/10.1248/bpb.33.1489

Saxena, S., Gautam, S. and Sharma, A. (2010). Physical, biochemical and antioxidant properties of some Indian honeys. Food Chemistry, 118(2), 391-397. https://doi.org/10.1016/j.foodchem.2009.05.001

Shafiee, S., Minaei, S., Moghaddam-Charkari, N. and Barzegar, M. (2014). Honey characterisation using computer vision system and artificial neural networks. Food Chemistry, 159, 143-150. https:// doi.org/10.1016/j.foodchem.2014.02.136

Shehu, A., Mohd, A.K.R., Aniza, A. and Salwani, I. (2015). Antibacterial activity and antioxidant capacity of Malaysian tualang honey. International Journal of Science and Research, 4(4), 1758-1762.

Silici, S., Sagdic, O. and Ekici, L. (2010). Total phenolic content, antiradical, antioxidant and antimicrobial activities of Rhododendron honeys. Food Chemistry, 121(1), 238-243. https://doi.org/10.1016/ j.foodchem.2009.11.078

Tan, H.T., Rahman, R.A., Gan, S.H., Halim, A.S., Asma'Hassan, S., Sulaiman, S.A. and Kirnpal-Kaur, B.S. (2009). The antibacterial properties of Malaysian tualang honey against wound and enteric microorganisms in comparison to manuka honey. BMC Complementary and Alternative Medicine, 9 (1), 34. https://doi.org/10.1186/1472-6882-9-34

Taormina, P.J., Niemira, B.A. and Beuchat, L.R. (2001). Inhibitory activity of honey against foodborne pathogens as influenced by the presence of hydrogen peroxide and level of antioxidant power. International Journal of Food Microbiology, 69(3), 217-225. https://doi.org/10.1016/S0168-1605(01) 00505-0 
Tumin, N., Halim, N.A., Shahjahan, M., Noor Izani, N.J., Sattar, M.A., Khan, A.H. and Mohsin, S.S.J. (2005). Antibacterial activity of local Malaysian honey. Malaysian Journal of Pharmaceutical Sciences, 3(2), 1-10.

Wilkinson, J.M. and Cavanagh, H.M. (2005). Antibacterial activity of 13 honeys against Escherichia coli and Pseudomonas aeruginosa. Journal of Medicine Food, 8(1), 100103. https://doi.org/10.1089/jmf.2005.8.100

Zainol, M.I., Yusoff, K.M. and Yusof, M.Y.M. (2013). Antibacterial activity of selected Malaysian honey. BMC Complementary and Alternative Medicine, 13 (1), 129. https://doi.org/10.1186/1472-6882-13-129

Zamora, M.C., Chirife, J. and Roldán, D. (2006). On the nature of the relationship between water activity and $\%$ moisture in honey. Food Control, 17(8), 642-647. https://doi.org/10.1016/j.foodcont.2005.04.002 